\title{
A rare case of primary cardiac lymphoma
}

\author{
Ayisha Mehtab Khan-Kheil, Hanif Muhammad Mustafa, Dhakshinamurthy \\ Vijay Anand, Prithwish Banerjee
}

Department of Cardiology, University Hospital Coventry \& Warwickshire, Coventry, UK

\section{Correspondence to} Dr Ayisha Mehtab Khan-Kheil, a.khan-kheil@nhs.net

Accepted 19 October 2015
CrossMark

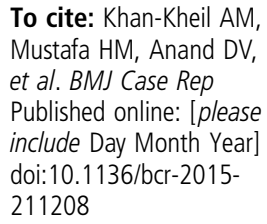

\section{SUMMARY \\ A 71-year-old man presented with shortness of breath and tachycardia along with systemic symptoms of weight loss and lethargy. A pulmonary embolus was the initial suspected diagnosis but through extensive investigations a rarer cause of his symptoms was identified. This case demonstrates the importance of cardiac imaging in the assessment and non-invasive tissue characterisation of a suspected cardiac tumour; in our case, this was subsequently confirmed by careful histological/ immunocytochemical evaluation of the pericardial effusion as a primary cardiac B-cell non-Hodgkin's lymphoma, thus enabling appropriate management leading to an excellent clinical outcome.}

\section{BACKGROUND}

Primary cardiac lymphoma is a rare disorder, making up only $1.3 \%$ of all malignant primary cardiac tumours. ${ }^{1}$ In contrast, disseminated lymphomas affecting the heart or metastases from other primary tumours are far more common. Symptoms can be non-specific and imaging is crucial to identifying the cause of this presentation. A tissue diagnosis can only be made from histology/ immunocytochemistry. Evidence so far has shown that, despite a poor prognosis, rituximab, cyclophosphamide, adriamycin, vincristine and prednisone (R-CHOP) chemotherapy is the main line of treatment. $^{2}$

\section{CASE PRESENTATION}

A 71-year-old retired man presented with a 2-week history of shortness of breath and palpitations, along with a 6-week history of lethargy and weight loss. There was no relevant medical history of note and he had been fit and well prior to the current illness.

On initial examination, there was no palpable lymphadenopathy, the chest was clear and heart sounds were audible with no added sounds or murmurs.

The patient was initially investigated for pulmonary embolus, however, a CT pulmonary angiogram demonstrated a large pericardial effusion with right ventricular (RV) compression. He was then referred to cardiology and transferred to the coronary care unit where the effusion was drained and bloodstained pericardial fluid sent for analysis.

\section{INVESTIGATIONS}

This patient underwent several investigations during his inpatient admission; the initial CT pulmonary angiogram demonstrated no filling defects in the pulmonary arteries but instead showed a large pericardial effusion with a maximal depth of $2 \mathrm{~cm}$, causing RV compression. The CT also noted that there were apparent filling defects in the right atrium (RA), which were presumed to be due to contrast mixing.

An echocardiogram then suggested a right atrial mass.

A cardiac MRI was performed, which showed a large multilobulated mass measuring up to $8.3 \mathrm{~cm}$ involving the RA and RV and atrioventricular groove extending and infiltrating the interatrial septum, tricuspid valve and basal interventricular septum (figure 1 and video 1). The mass was also shown to extend into the pericardium and inferior vena cava, and to cause obstruction to the RV inflow. Left ventricular function was mildly impaired with an ejection fraction of $53 \%$. The tissue characterisation on cardiac MRI suggested that the mass was either a primary cardiac lymphoma or a sarcoma.

The blood-stained pericardial fluid was sent for cytology, using alcohol fixation, with appropriate controls performed. This confirmed atypical lymphoid cells (figure 2) that were positive for CD45 and CD20. Background CD3 cells were seen and there were scattered reactive mesothelial cells that showed immunoreactivity to $\mathrm{CK} 5 / 6$ and calretinin. These findings on immunophenotyping were felt to be suggestive of a lymphoproliferative disorder, most likely a B-cell non-Hodgkin's lymphoma (figure 3).

Flow cytometry was also performed, which demonstrated a population of lymphocytes with bright CD45 and low side scatter in the pericardial fluid.

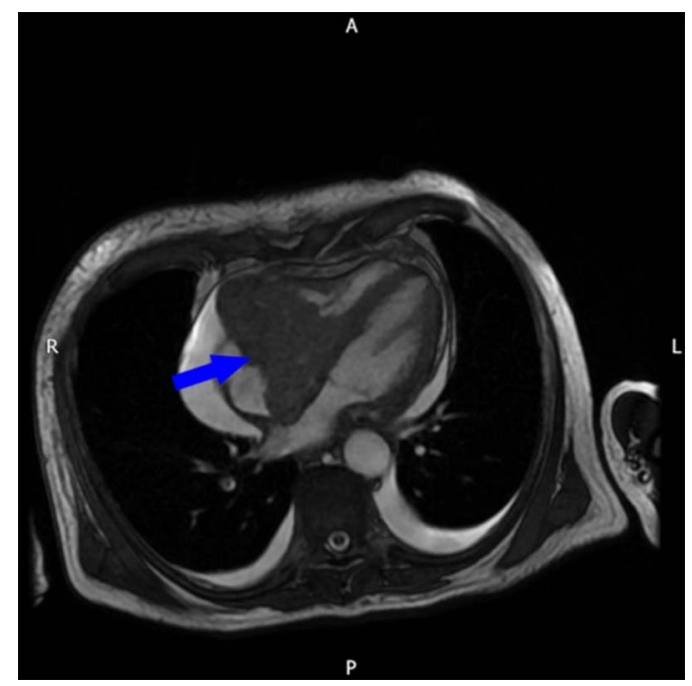

Figure 1 Cardiac MRI, four-chamber view, showing a large right atrioventricular mass. 


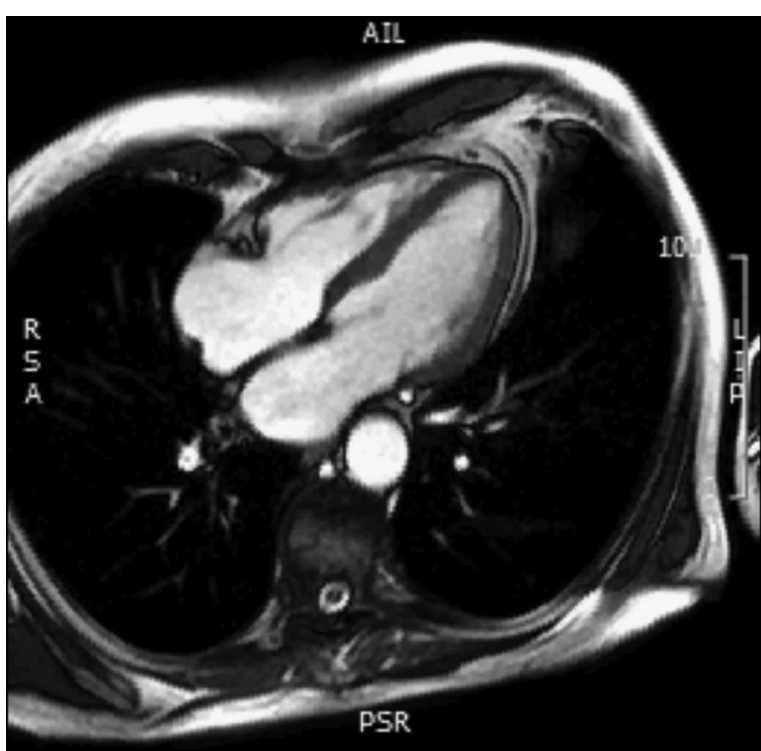

Video 1 Cardiac MRI, four-chamber view, of the lymphoma prior to treatment.

The final investigation was a cardiac biopsy in order to obtain a tissue diagnosis of the mass. The results of this, however, only confirmed that it was necrotic tissue, making this test unhelpful. The possibility of a second biopsy was discussed with the haematologists, but it was felt that the immunohistochemistry results were sufficient to instigate treatment and that a further biopsy was not needed.

In terms of blood tests, full blood count and renal function were entirely normal. Alkaline phosphatase was raised at $281 \mathrm{U} / \mathrm{L}$ with normal bilirubin. Lactic acid dehydrogenase was raised at $1880 \mathrm{iU} / \mathrm{L}$, likely of cardiac origin.

\section{DIFFERENTIAL DIAGNOSIS}

In a patient presenting with an atrial mass, the initial diagnosis is often atrial myxoma, however, this usually affects the left side of the heart in $75 \%$ of cases and is slow growing and benign.

The other important differential, distinguishable through MRI, is angiosarcoma, which is the commonest primary malignant cardiac tumour. Angiosarcomas are aggressive lesions arising in the RA in $75 \%$ of patients; these lesions can infiltrate the great vessels or coronary arteries.

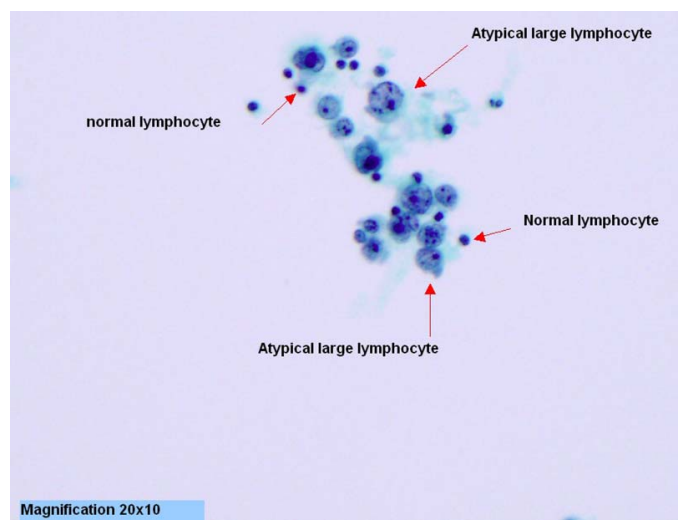

Figure 2 Histology slide of pericardial fluid depicting atypical lymphocytes.

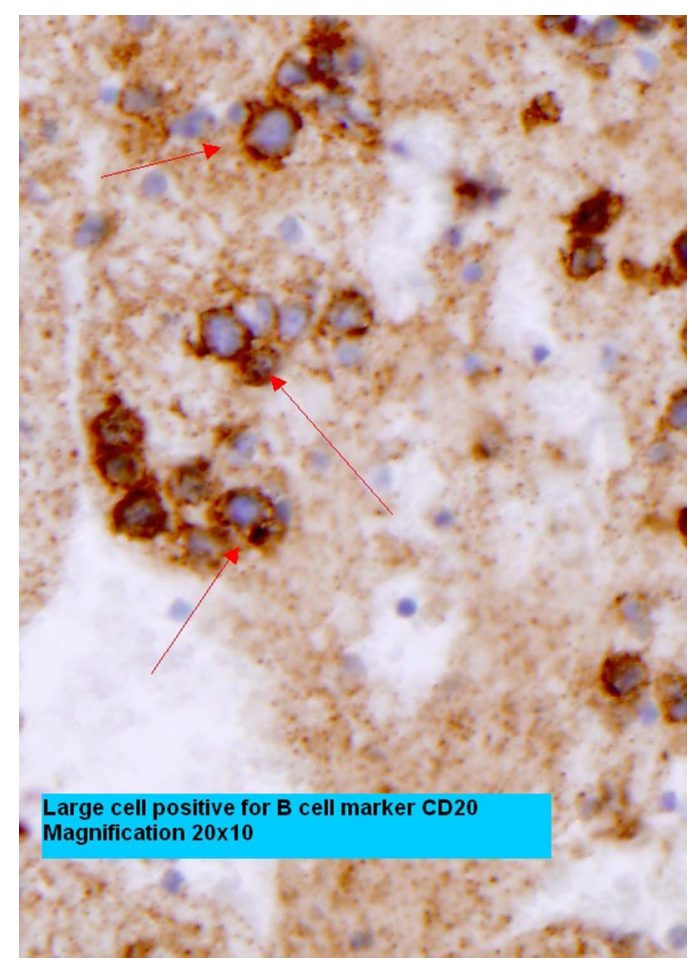

Figure 3 Histology slide demonstrating immunocytochemical staining of pericardial fluid depicting CD20 positive B cells.

Finally, in a patient presenting with malaise and weight loss, other primary malignancies need to be excluded; but in our case, there were no other sources of primary malignancy identified on a subsequent CT of the chest, abdomen and pelvis, and there was no nodal involvement.

\section{TREATMENT}

In the absence of a direct biopsy specimen of the right atrial mass, the immunophenotyping of the pericardial fluid was felt to be conclusive of the diagnosis of primary B-cell lymphoma. The optimal regimen to be used in such cases is rituximab in combination with CHOP chemotherapy.

\section{OUTCOME AND FOLLOW-UP}

The patient attended for chemotherapy on a 3-weekly basis; he reported that his symptoms in terms of the shortness of breath and lethargy had greatly improved. An echocardiogram performed after the first cycle of chemotherapy already showed a reduction in size of the cardiac tumour and pericardial effusion.

R-CHOP chemotherapy was started for eight cycles in total. The patient had a follow-up cardiac MRI after seven cycles, which demonstrated complete resolution of the RV/RA mass (video 2).

\section{DISCUSSION}

In 1977, McAlliser and Fenoglio ${ }^{3}$ defined primary cardiac lymphoma as an extranodal lymphoma involving only the heart and or pericardium. Primary cardiac lymphoma often arises from the right side of the heart, therefore infiltrating the RA or $\mathrm{RV}^{4}$ In immunocompetent hosts, primary cardiac lymphoma is normally of a B-cell non-Hodgkin's type. Cardiac tumours can present with chest pain, arrhythmias, heart failure and even sudden death, in addition to the generalised symptoms of weight loss and malaise. ${ }^{5}$ 


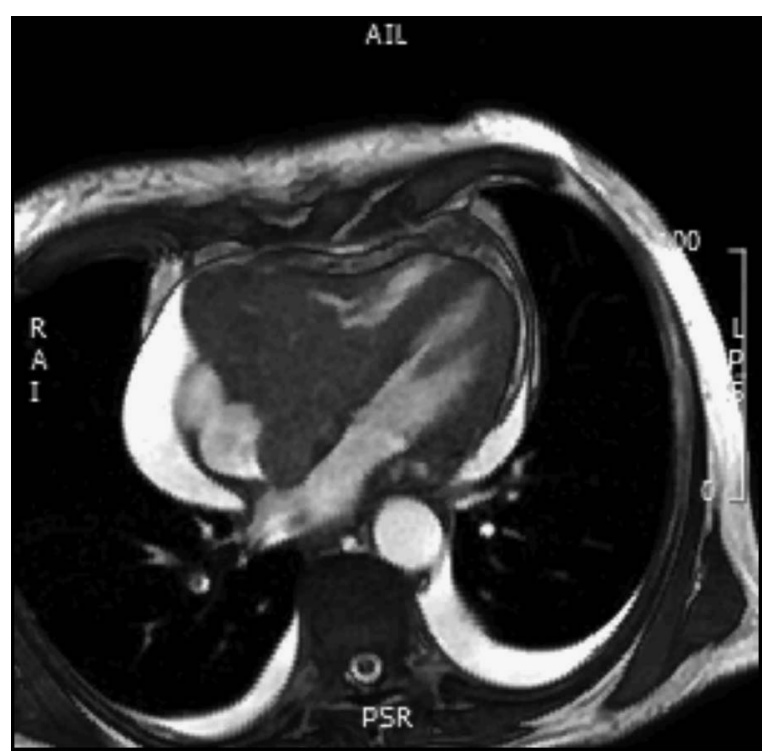

Video 2 Cardiac MRI, four-chamber view, post seven cycles of rituximab, cyclophosphamide, adriamycin, vincristine and prednisone (R-CHOP) chemotherapy, demonstrating complete resolution of lymphoma. Cardiac MRI demonstrating resolution of previous mass after treatment.

Cardiac tumours are rare but important diagnoses that must not be missed. As can be seen from this case, the initial presentation can produce several differential diagnoses and it is through thorough investigation that the final diagnosis was reached. Fluid sample analyses are crucial to reaching a diagnosis and in one study, $67 \%$ of patients who had pericardial fluid analysed yielded a positive result for atypical lymphoid cells, which then underwent further immunological testing to confirm monoclonal cell populations. ${ }^{6}$

Diagnosis very much depends on multiple imaging modalities and tissue or fluid diagnosis in order to establish an exact diagnosis and commence treatment. Despite the prognosis being poor, response to R-CHOP chemotherapy has, in some cases, led to a $50 \%$ decrease in tumour size. $^{7}$ Other case reports suggest that a treatment approach involving debulking surgery in addition to chemotherapy and radiation therapy can prolong survival for up to 5 years. ${ }^{8}$

\section{Learning points}

- It is important to considering rarer diagnoses in the differential diagnosis list for a patient presenting with shortness of breath and weight loss.

- The significance of pericardial fluid analysis and immunological phenotyping in order to establish a diagnosis cannot be ignored.

- Various cardiac imaging modalities such as transthoracic echocardiography, CT and MRI play a complementary role in investigating a cardiac mass.

Competing interests None declared.

Patient consent Obtained.

Provenance and peer review Not commissioned; externally peer reviewed.

\section{REFERENCES}

1 Johri A, Baetz T, Isotalo PA, et al. Primary cardiac diffuse large B cell lymphoma presenting with superior vena cava syndrome. Can J Cardiol 2009;25:e210-12.

2 Miguel CE, Bestetti RB. Primary cardiac lymphoma. Int J Cardiol 2011;149:358-63.

3 McAlliser HA, Fenoglio JJ. Tumours of the cardiovascular system. In: Atlas of tumour pathology. 2nd series. Fascicle 15. Washngton DC: Armed Forces Institute of pathology, 1978:99-100.

4 Matos AP, Palas J, Doulaptsis $C$, et al. B cell lymphoma of the heart: a rare diagnosis. Rev Port Cadiol 2014;33:803.e1-3.

5 Habertheuer A, Ehrlich M, Wiedemann D, et al. A rare case of primary cardiac B cell Iymphoma. J Cardiothorac Surg 2014;9:14.

6 Giovanni $\mathrm{CL}$, et al. Primary cardiac lymphoma in immunocompetent patients. Cancer $1997 ; 80$.

7 Chim CS, Chan ACL, Kwong YL, et al. Primary cardiac lymphoma. Am J Haematol 1997:54:79-83.

8 Gowda RM, Khan IA. Clinical perspectives of primary cardiac lymphoma. Angiology 2003;54:599-604.

Copyright 2015 BMJ Publishing Group. All rights reserved. For permission to reuse any of this content visit

http://group.bmj.com/group/rights-licensing/permissions.

BMJ Case Report Fellows may re-use this article for personal use and teaching without any further permission.

Become a Fellow of BMJ Case Reports today and you can:

- Submit as many cases as you like

- Enjoy fast sympathetic peer review and rapid publication of accepted articles

- Access all the published articles

- Re-use any of the published material for personal use and teaching without further permission

For information on Institutional Fellowships contact consortiasales@bmjgroup.com

Visit casereports.bmj.com for more articles like this and to become a Fellow 